\title{
Bony canal and grooves of the middle meningeal artery: mythic structures in anatomy and neurosurgery?
}

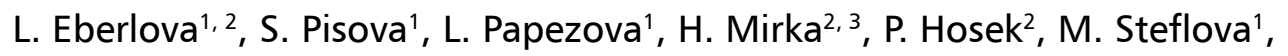
A. Maleckova ${ }^{4}$, D. Kachlik ${ }^{5}$, D. Stepanek ${ }^{6}$

'Department of Anatomy, Faculty of Medicine in Pilsen, Charles University, Pilsen, Czech Republic ${ }^{2}$ Biomedical Centre, Faculty of Medicine in Pilsen, Charles University, Pilsen, Czech Republic ${ }^{3}$ Department of Imaging Methods, University Hospital in Pilsen, Czech Republic ${ }^{4}$ Department of Histology and Embryology, Faculty of Medicine in Pilsen, Charles University, Pilsen, Czech Republic ${ }^{5}$ Department of Anatomy, $2^{\text {nd }}$ Faculty of Medicine, Charles University, Prague, Czech Republic

${ }^{6}$ Department of Neurosurgery, University Hospital in Pilsen, Czech Republic

[Received: 14 June 2019; Accepted: 4 August 2019]

Background: It has been previously published that the frontal branch of the middle meningeal artery (MMA) is usually embedded in a bony canal (BC). Although the incidence of the $B C$ was over $70 \%$, this structure is currently omitted both in anatomical nomenclature and in most of the literature. We found the same gap pertaining to the grooves for the MMA on the skull base. The aims of our study were to assess the incidence and morphometry of the MMA BC and grooves on the skull base.

Materials and methods: Computed tomography (CT) scans of 378 patients, 172 skull bases as well as 120 sphenoidal bones and 168 temporal bones, and 12 histological specimens from 3 men and 3 women and 3 different regions of the MMA course were assessed.

Results: Based on CT scans, the incidence of the BC was $85.44 \%$ and was significantly higher in females than in males. Most of the canals and grooves were bilateral. The mean canal length was $17.67 \mathrm{~mm}$, the mean transverse diameter $1.33 \mathrm{~mm}$, and the mean distance from the superior orbital fissure (dFOS) was $26.7 \mathrm{~mm}$. In the skull bases, the BC incidence was $70.07 \%$, the mean canal length $10.74 \mathrm{~mm}$, and the mean dFOS was $19.16 \mathrm{~mm}$. The groove for the MMA on the temporal and sphenoidal bones was present in $99.42 \%$ and $95.35 \%$, respectively. Histological specimens confirmed the presence of the MMA and accompanying vein/s. Conclusions: Based on our results, we suggest the addition of the $B C$ and grooves for the middle meningeal vessels to the upcoming version of the Terminologia Anatomica. (Folia Morphol 2020; 79, 3: 450-461)

Key words: anatomical terminology, middle meningeal artery, skull base, Terminologia Anatomica

\section{INTRODUCTION}

The middle meningeal artery (MMA) is very important in the development and treatment of a variety of diseases, e.g. epidural haematoma, arteriovenous fistula, meningioma, aneurysm, and migraine. Because the ophthalmic artery may variably originate

Address for correspondence: Dr. L. Eberlova, Department of Anatomy, Faculty of Medicine in Pilsen, Charles University, Karlovarska 48, 30166 Pilsen, Czech Republic, tel: +420 377593302, e-mail: lada.eberlova@lfp.cuni.cz 


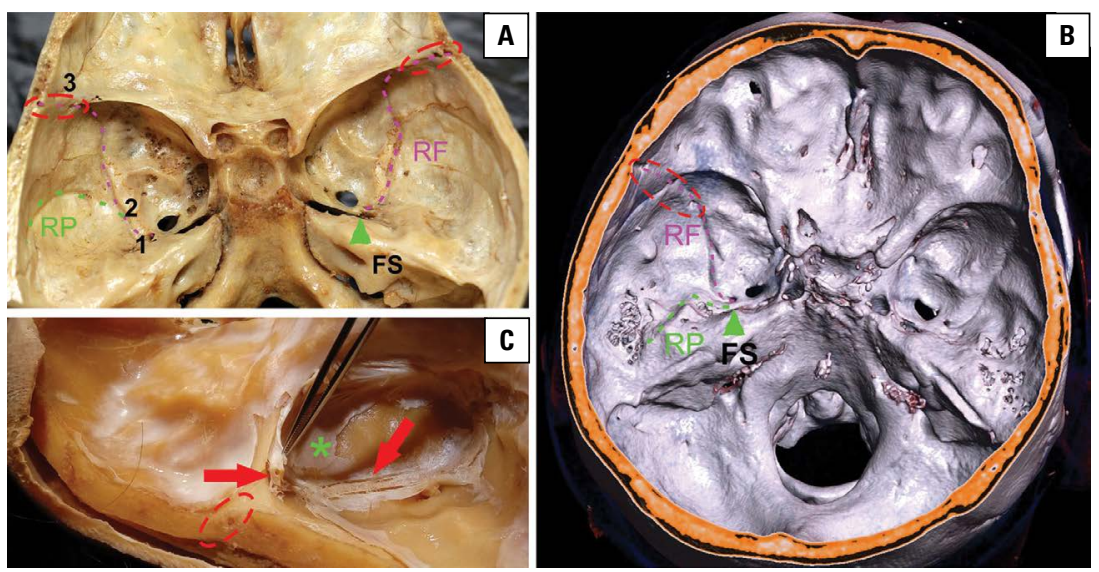

Figure 1. Base of the human skull. Foramen spinosum (FS, green arrowhead), frontal branch of the middle meningeal artery (RF), parietal branch of the middle meningeal artery (RP), the bony canal (red ellipse). A. Sampling sites: foramen spinosum (1), groove for the middle meningeal artery (2), the bony canal (3); B. Computed tomography, volume-rendering technique; C. Meningeal vessels (red arrow), dura mater (green asterisk).
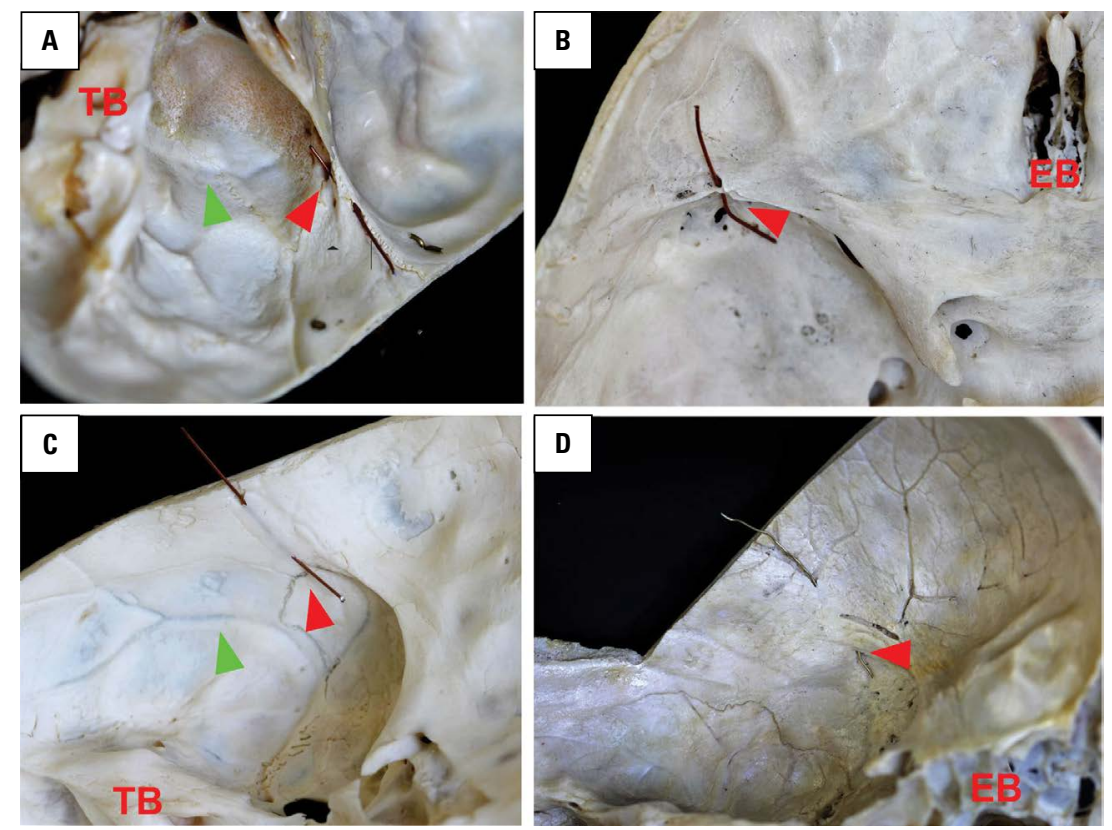

Figure 2. Base of the human skull, distinctive bony canal variability: along the lesser wing of the sphenoidal bone (A), transversally the lesser wing of the sphenoidal bone (B), on the parietal bone (C), and connecting the sphenoidal with the parietal bone (D). Bony canal (red arrowhead), groove for the middle meningeal artery (green arrowhead), temporal bone (TB), ethmoidal bone (EB).

from the MMA [5], special caution must be taken to avoid damage to this artery during surgery [37].

Although variable origins of the MMA have been described [6], it most commonly arises from the mandibular part of the maxillary artery. It ascends medially to the lateral pterygoid muscle, passes through the loop of the auriculotemporal nerve and enters the middle cranial fossa through the foramen spinosum. Intracranially, the middle meningeal vessels run within the extradural space and their wall is very firmly adhered to the dura mater and periosteum [26a]. About
$2.5 \mathrm{~cm}$ from the foramen spinosum, the MMA bifurcates into the frontal and parietal branches (Fig. 1A, B). The larger frontal branch continues ventrally, crosses the greater wing of the sphenoid, and travels laterally along the superior orbital fissure (FOS) towards the pterion, near which it embeds into the sphenoparietal groove or canal of Trolard [26a, 29], which is one of the objects of interest of our study (Figs. 1, 2). Although the bony canal (BC) for the frontal branch of the MMA has been studied before and its incidence in recent studies exceeded 70\% (Table 1), these studies 
Table 1. Bony canal of the middle meningeal artery — literature review

\begin{tabular}{|c|c|c|c|c|c|c|}
\hline Number assessed & Device & $\begin{array}{l}\text { Incidence (canal at } \\
\text { least unilaterally) }\end{array}$ & $\begin{array}{c}\text { Mean BC } \\
\text { length [mm] }\end{array}$ & $\begin{array}{c}\text { Mean dFOS } \\
{[\mathrm{mm}]}\end{array}$ & BC location & Reference \\
\hline- & - & - & $3-10$ & - & - & [29] \\
\hline 50 skulls & - & $54 \%$ & 10-20 & - & Sphenoparietal suture & [21] \\
\hline 907 cranial halves & - & $59.6 \%$ & $1-15$ & - & $\begin{array}{c}\text { 39\% posterior to PTR, } \\
14 \% \text { PTR, } 31 \% \text { anterior to PTR }\end{array}$ & {$[3]$} \\
\hline 39 skulls & Calliper & $75.6 \%$ & 12.2 & 18.9 & $\begin{array}{l}\text { On the temporal side of the } \\
\text { lesser wing of the sphenoid }\end{array}$ & [25] \\
\hline 20 CT scans & - & $80 \%$ & 11.6 & - & - & [25] \\
\hline 19 skulls & Calliper & $78 \%$ & 11.7 & - & Lesser wing of the sphenoid & [2] \\
\hline 378 CT scans & - & $85.5 \%$ & 17.7 & 26.7 & - & Our results (Table 3) \\
\hline 172 skull bases & Flexible ruler & $82.5 \%$ & 10.74 & 19.16 & Fig. 7 & Our results (Table 3) \\
\hline
\end{tabular}

$\mathrm{BC}$ - bony canal; $\mathrm{CT}$ — computed tomography; dFOS — distance from the superior orbital fissure; PTR — pterion

Table 2. Contributions to Terminologia Anatomica [9] focused on the clinical or neuroanatomy published since 1999

\begin{tabular}{lcc}
\hline Topic & Year & Reference \\
\hline General and clinical anatomy & 1999 & {$[36]$} \\
General and clinical anatomy & 2008 & {$[13]$} \\
Clinical anatomy & 2009 & {$[14]$} \\
Anatomical terminology in English & 2009 & {$[35]$} \\
FCAT — on-line anatomical terminology & 2010 & {$[18]$} \\
FCAT — international anatomical terminology & 2011 & {$[8]$} \\
Systemic, topographic and clinical anatomy & 2015 & {$[15]$} \\
General anatomy and anatomical variations & 2016 & {$[16]$} \\
Nervous system and senses & 2017 & {$[17]$} \\
Neuroanatomy & 2017 & {$[10,28]$} \\
\hline
\end{tabular}

FCAT — Federative Committee on Anatomical Terminology

do not offer any histological assessment; additionally, in contemporary anatomical terminology and in the literature, this structure is either omitted (Table 2 ) [9a, 13a], or imprecisely depicted [7a, b; 20a, b; 24a, 26a]. During the literature review, we found that a similar situation applies also to the grooves for the MMA on the base of the skull and the separate sphenoidal and temporal bones [7a, c; 9a-c; 24b]. However, knowledge of these grooves is important for radiologists to differentiate a normal finding from a fracture [11]. Therefore, to broaden this knowledge, and to contribute to more complete anatomical terminology - the groove for the MMA is presently depicted in Terminologia Anatomica (TA) only on the parietal bone [9b] - we assessed the incidence of the grooves for the MMA on the base of the skull as well as on the separate sphenoidal and temporal bones.
The aims of our study were: (1) To assess the incidence and to obtain morphometric measurements of the MMA bony canal from computed tomography (CT) scans and from adult human skull bases; (2) To assess the incidence of the grooves of the MMA in the middle cranial fossa on adult skull bases and on the temporal and sphenoidal bones independently; (3) To confirm the presence of the MMA in the bony canal and grooves on the skull base histologically.

\section{MATERIALS AND METHODS}

All human skulls and bones, cadavers, as well as histological specimens, medical records and cranial CT images used in our study were obtained and processed in accordance with the legislation of the Czech Republic as well as with the Code of Ethics of the World Medical Association (Declaration of Helsinki).

Non-contrast head CT scans of 378 patients (288 men, 90 women) taken at the University Hospital in Pilsen in 2013 and 2014 for suspected craniocerebral trauma were assessed. The scans were obtained with a multi-slice CT scanner (Somatom Sensation 64, Siemens, Forchheim, Germany) and were evaluated using Syngo.via software (Siemens, Forchheim, Germany). Bony canal incidence $(n=378)$ was examined in thin axial slices (thickness $0.6-0.75 \mathrm{~mm}$, high-resolution CT image reconstruction algorithm). The canal length ( $n=266)$, transverse diameter ( $n=31$ ) and distance from the lateral margin of the superior orbital fissure $(n=31)$ were measured using multiplanar reformations (Table 3, Fig. 3).

Skull bases were assessed for sex in the following way. Male sex estimation was based on the predominance of following signs: more pronounced 
Table 3. Bilateral canal morphometry in computed tomography scans (black) and skull bases (red), dimensions in $\mathrm{mm}$

\begin{tabular}{|c|c|c|c|c|c|c|c|c|c|c|}
\hline & \multicolumn{3}{|c|}{ Number of canals } & \multicolumn{3}{|c|}{ Mean } & \multirow{2}{*}{$\begin{array}{c}\text { Median } \\
17.08\end{array}$} & \multirow{2}{*}{$\begin{array}{c}\text { Maximum } \\
36.2\end{array}$} & \multirow{2}{*}{$\frac{\text { Minimum }}{5.2}$} & \multirow{2}{*}{$\begin{array}{c}\text { SD } \\
5.64\end{array}$} \\
\hline Canal length & 207 & 59 & 266 & 17.66 & 17.54 & 17.67 & & & & \\
\hline Transverse diameter & 23 & 8 & 31 & 1.33 & 1.33 & 1.33 & 1.2 & 2.5 & 0.7 & 0.51 \\
\hline dFOS & 23 & 8 & 31 & 27.3 & 24.9 & 26.7 & 27.0 & 42.5 & 13.0 & 0.72 \\
\hline Canal length & 86 & 68 & $167^{*}$ & 11.00 & 10.63 & 10.74 & 10.00 & 24.00 & 2.00 & 5.92 \\
\hline dFOS & 40 & 30 & $79^{*}$ & 19.70 & 19.03 & 19.16 & 20.00 & 35.00 & 3.00 & 6.26 \\
\hline
\end{tabular}

Blue — men; pink — women; white — both sexes ( ${ }^{*}$ skulls with the same number of male and female characters including); dFOS — distance from the lateral margin of the superior orbital fissure; $S D$ - sample standard deviation
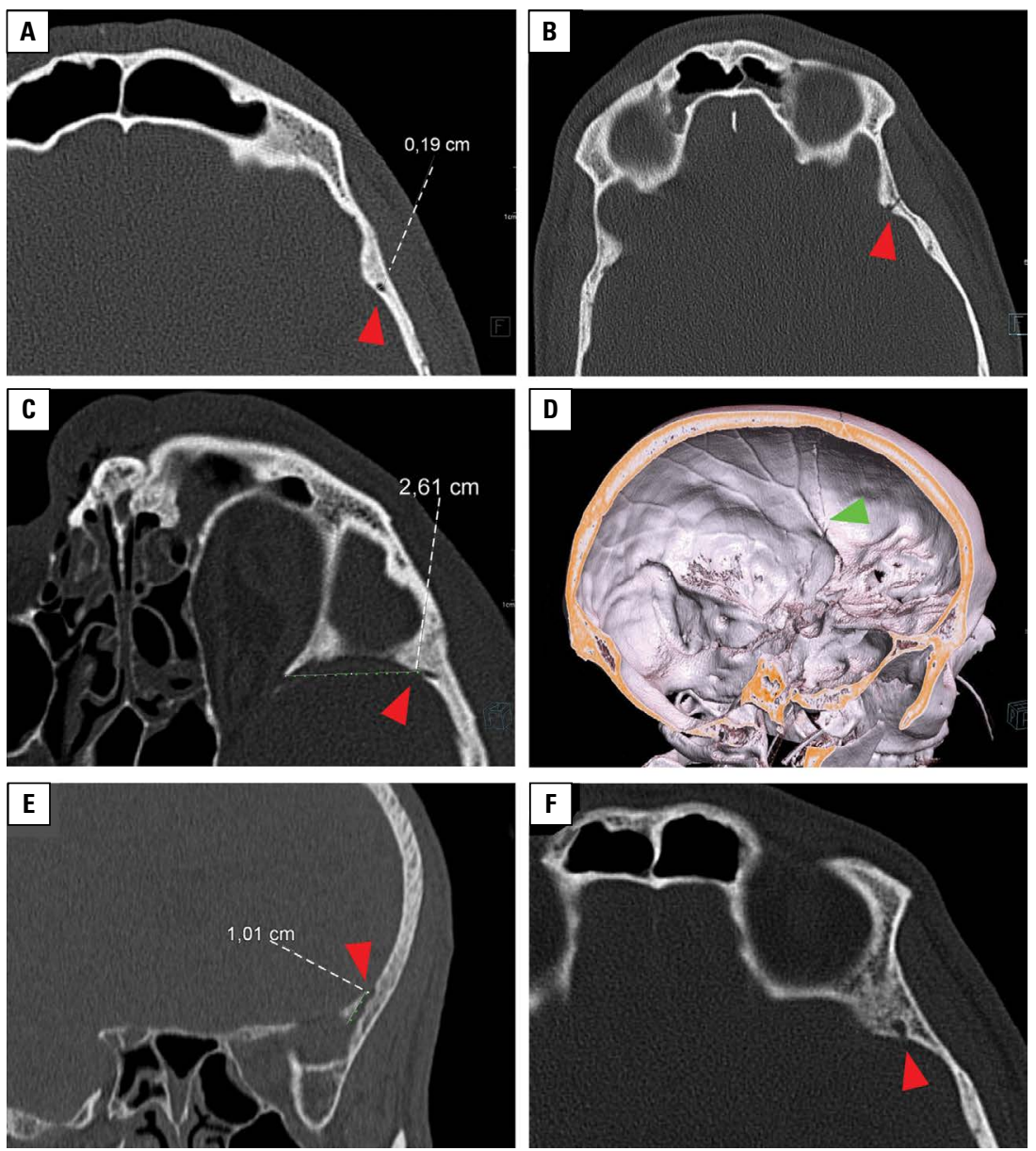

Figure 3. Head, computed tomography images in axial (A-C, F), coronal (E) and volume-rendering technique (D). Bony canal (red arrowhead). Canal morphometric assessment: transverse diameter $(\mathbf{A})$, distance from the superior orbital fissure (C), canal length $(\mathbf{E})$; fracture passing through the canal (B, D, green arrowhead), deep groove approaching a canal (F).

nasofrontal angle, more robust supercilary arches, mastoid processes and external occipital protuberances [26c]. If the same number of male and female characters were present, the skulls were assessed as "indifferent". In skull bases ( $\mathrm{n}=172$ : 81 male, 72 female, 19 indifferent), the BC incidence and the MMA impressions on the sphenoidal and temporal bones were assessed. In 65 skulls ( 32 male, 25 female, 8 indifferent) of the same cohort, BC initiation and termination were evaluated. For the distance from the superior orbital fissure $(n=79)$ and the $B C$ length measurements ( $n=167$ ), a flexible ruler was used to copy the skull base concavity. For the statistical analysis, the skulls with either sex indifference (i.e., presence of 2 male and 2 female characters) or the $\mathrm{BCs}$ cut by the removal of the skull vault were excluded from the sex (length) related analysis, respectively. For the MMA groove evaluation, 120 sphenoid bones 
(60 right, 60 left) and 168 temporal bones (88 right and 80 left) were evaluated.

For the histological assessment, from the cadavers (3 men, 3 women) used for education in our Department of Anatomy, we obtained fixed samples $(n=12)$ of the meningeal vessels from three different regions (Fig. 1A): 1. next to the foramen spinosum, 2. from the vessel bifurcation, and 3. from the bony canal. For decalcification, Komplexon III (EDTA disodium salt 14\% solution, pH 7-7.4; Penta, Pardubice, Czech Republic) with $1.4 \%$ solution sodium hydroxide (Penta, Pardubice, (zech Republic) was used. For tissue blocks sized $\sim 1 \mathrm{~cm}^{3}$, incubation for $6-8$ weeks at room temperature was performed. Decalcified specimens were dehydrated in graded ethanol solutions and embedded in paraffin (Leica processor TP1020, Nussloch, Germany). Tissue blocks were cut transversely into $4 \mu \mathrm{m}$ sections (Leica Microtome RM2255, Nussloch, Germany), mounted on Super Frost slides coated with 3-aminopropyltriethoxysilane (Sigma Aldrich, Vienna, Austria), deparaffinized, rehydrated, and processed as follows: two sections per tissue block were stained with haematoxylin and eosin (BioGnost, Zagreb, Croatia), and two sections were stained with Verhoeff's haematoxylin-green trichrome (Merck KGaA, Darmstadt, Germany) to differentiate elastic and collagen fibres.

\section{Statistical analysis}

For the statistical analysis, the Fisher's exact test, Mann-Whitney $\mathrm{U}$ test, paired t-test, and the Wilcoxon signed-rank test were performed. All reported $p$ values were two-tailed, and the level of statistical significance was set at $\alpha=0.05$. Confidence intervals of proportions (i.e., population incidence estimates) were calculated using the method of Agresti and Coull [1].

\section{RESULTS}

\section{Bony canal incidence based on the CT scans}

Of the 378 patients, $323(85.44 \%)$ had at least a unilateral BC (Table 4). An exclusively unilateral canal was present in $34.13 \%$ of the patients (Table 5); the canal was present bilaterally in $51.32 \%$ of the patients (Table 6). Both the incidence of bilateral canals and the general $\mathrm{BC}$ incidence (i.e., at least one canal present on any side) were significantly higher in females (Tables 4, 6). This result is in accordance with the apparent tendency for a bilateral canal occurrence, i.e., the presence of a canal indicates a $70 \%$ chance that the same structure is present on the other side (Table 7a). There was no significant relationship
Table 4. Bony canal present at least unilaterally in computed tomography scans (black) and skull bases (red)

\begin{tabular}{llll}
\hline & Canal present & Absent & Total \\
\hline Men & $239 / 52$ & $49 / 19$ & $288 / 71$ \\
Women & $84 / 37$ & $6 / 19$ & $90 / 56$ \\
Total & $323 / 89$ & $55 / 38$ & $378 / 127$ \\
\hline
\end{tabular}

$p=0.016$ : higher incidence of bony canals in women; $p=0.437$

Table 5. Exclusively unilateral bony canal incidence in computed tomography scans (black) and skull bases (red)

\begin{tabular}{lccc}
\hline & Unilateral canal & Bilateral or absent & Total \\
\hline Men & $102 / 25$ & $186 / 46$ & $288 / 71$ \\
Women & $27 / 13$ & $63 / 43$ & $90 / 56$ \\
Total & $129 / 38$ & $249 / 89$ & $378 / 127$ \\
\hline
\end{tabular}

$p=0.375 ; p=0.17$ : unilateral bony canals are not related to sex

Table 6. Bilateral bony canal incidence in computed tomography scans (black) and skull bases (red)

\begin{tabular}{lccc}
\hline & Bilateral canal & Unilateral or absent & Total \\
\hline Men & $137 / 27$ & $151 / 44$ & $288 / 71$ \\
Women & $57 / 24$ & $33 / 32$ & $90 / 56$ \\
Total & $194 / 51$ & $184 / 76$ & $378 / 127$ \\
\hline
\end{tabular}

$p=0.011$ : incidence of bilateral bony canals is higher in women; $p=0.590$

between sex and the number of $\mathrm{BCs}$ (in patients with at least unilaterally occurring $\mathrm{BC}$ ) or between sex and the laterality of unilaterally occurring BCs (Table 8).

\section{Bony canal and grooves for the MMA in human skull bases and separate bones}

Of 172 skull bases (those with the BC cut were excluded) $70.07 \%$ had at least a unilateral BC (Table 4). The canal was present unilaterally in $29.92 \%$ of the skulls (Table 5) and bilaterally in $40.16 \%$ (Table 6). Unilateral canals in women, but not men, were more often found on the right side (Table 8). A general tendency to the higher $B C$ incidence in women was not proved; however, the presence of the canal on one side increases the probability for a bilateral BC occurrence also in the skull bases (Table 7a).

The groove for the MMA was assessed on 172 skull bases (i.e., 172 right temporal, 172 left temporal and 172 sphenoidal bones). The incidence reached $99.42 \%$ on the temporal bones and $95.35 \%$ on the sphenoidal bones. On the separate bones, the inci- 
Table 7a. Bony canal right-left coincidence in computed tomography scans (black) and skull bases (red)

\begin{tabular}{lccc}
\hline Side incidence & $\begin{array}{c}\text { Right canal } \\
\text { present }\end{array}$ & $\begin{array}{c}\text { Right canal } \\
\text { absent }\end{array}$ & Total \\
\hline Left canal present & $194 / 54$ & $62 / 17$ & $256 / 71$ \\
Left canal absent & $67 / 26$ & $55 / 43$ & $122 / 69$ \\
Total & $261 / 80$ & $117 / 60$ & $378 / 140$ \\
\hline
\end{tabular}

$p=0.0001 ; p<0.0001$ : presence of the canal on one side increases the probability of a contralateral canal

Table 7b. Impression (imp.) on the sphenoidal bone right-left coincidence (skulls)

\begin{tabular}{lccc}
\hline & Right imp. present & Right imp. absent & Total \\
\hline Left imp. present & 138 & 11 & 149 \\
Left imp. absent & 15 & 8 & 23 \\
Total & 153 & 19 & 172 \\
\hline
\end{tabular}

$p=0.0001$ : presence of the groove on one side increases the probability of a contralateral groove

Table 7c. Impression (imp.) on the temporal bone right-left coincidence (skulls)

\begin{tabular}{lccc}
\hline & Right imp. present & Right imp. absent & Total \\
\hline Left imp. present & 171 & 0 & 171 \\
Left imp. absent & 0 & 1 & 1 \\
Total & 171 & 1 & 172 \\
\hline
\end{tabular}

$p=0.0058$ : presence of the groove on one side increases the probability of a contralateral groove

Table 7d. Impression (imp.) on the sphenoidal bone right-left coincidence (bones)

\begin{tabular}{lccc}
\hline & Right imp. present & Right imp. absent & Total \\
\hline Left imp. present & 38 & 6 & 44 \\
Left imp. absent & 7 & 9 & 16 \\
Total & 45 & 15 & 60 \\
\hline
\end{tabular}

$p=0.0017$ : presence of the groove on one side increases the probability of a contralateral groove

Table 8. Laterality of unilateral bony canals $(\mathrm{BC})$ with respect to gender in computed tomography scans (black) and skull bases (red)

\begin{tabular}{lccc}
\hline & Unilateral BC right side & Unilateral BC left side & Total \\
\hline Men & $49 / 12$ & $53 / 13$ & $102 / 25$ \\
Women & $13 / 12$ & $14 / 1$ & $27 / 13$ \\
Total & $62 / 24$ & $67 / 14$ & $129 / 38$ \\
\hline
\end{tabular}

$p=1 ; p=0.0118$ : Unilateral canal in women is more frequent on the right side dence was $95.83 \%$ and $82.5 \%$, respectively. Both on the separate bones and on the skull bases, there was a strong tendency for a bilateral groove occurrence (Tables 7b-d).

\section{Bony canal morphometry based on the CT scans and human skull bases}

The mean canal length in the CT scans was $17.67 \mathrm{~mm}$, and in the skulls, the mean length was $10.74 \mathrm{~mm}$ (Table 3). In the CT scans, the mean canal diameter was $1.33 \mathrm{~mm}$ and the mean distance from the FOS was $26.7 \mathrm{~mm}$. In the skull bases, the mean canal length was $10.74 \mathrm{~mm}$ and the distance from the FOS was $19.16 \mathrm{~mm}$. No significant differences were found in the transverse diameter, length, laterality, sex or distance from the FOS between the bi- and unilateral canals in the CT scans (Fig. 4). In the skulls (Fig. 5A, E), dFOS was higher on the right side $(p=0.036)$, and the bilateral canals were longer $(p=0.028)$. The $\mathrm{BC}$ beginning was most often found in the pterion $(41.5 \%)$ and the end was most often on the parietal bone (Fig. 6).

\section{Histology}

Histological specimens obtained from three different locations (Fig. 1A) traced the course of the MMA and confirmed its presence both on the base of the skull and in the BC (Fig. 7).

\section{DISCUSSION}

Bony canal and grooves of the middle meningeal vessels in the literature

A bony tunnel for the MMA is not a newly discovered structure (Table 1). It is presumed to have been first identified by Trolard in 1890 [29]. A detailed description of the course and branching of the MMA was subsequently provided by Plummer in 1896 [21]. Morris and Jackson [19], in their textbook on anatomy, described the anterior branch of the MMA passing through a groove on the greater wing of the sphenoid bone: "The groove deepens and is often covered by a thin plate of bone." This description corresponds also to our findings; specifically, in most of the CT scans assessed, there was either a canal or a noticeable groove in the corresponding location (Fig. 3). The BC is drawn (but not designated) in the Atlas of Human Anatomy $[20 a, 24 a]$ and in the Pocket Atlas of Anatomy [9a]. In contrast, it is described (but not drawn) in Gray's Anatomy [26a]. In Bergman's Comprehensive 

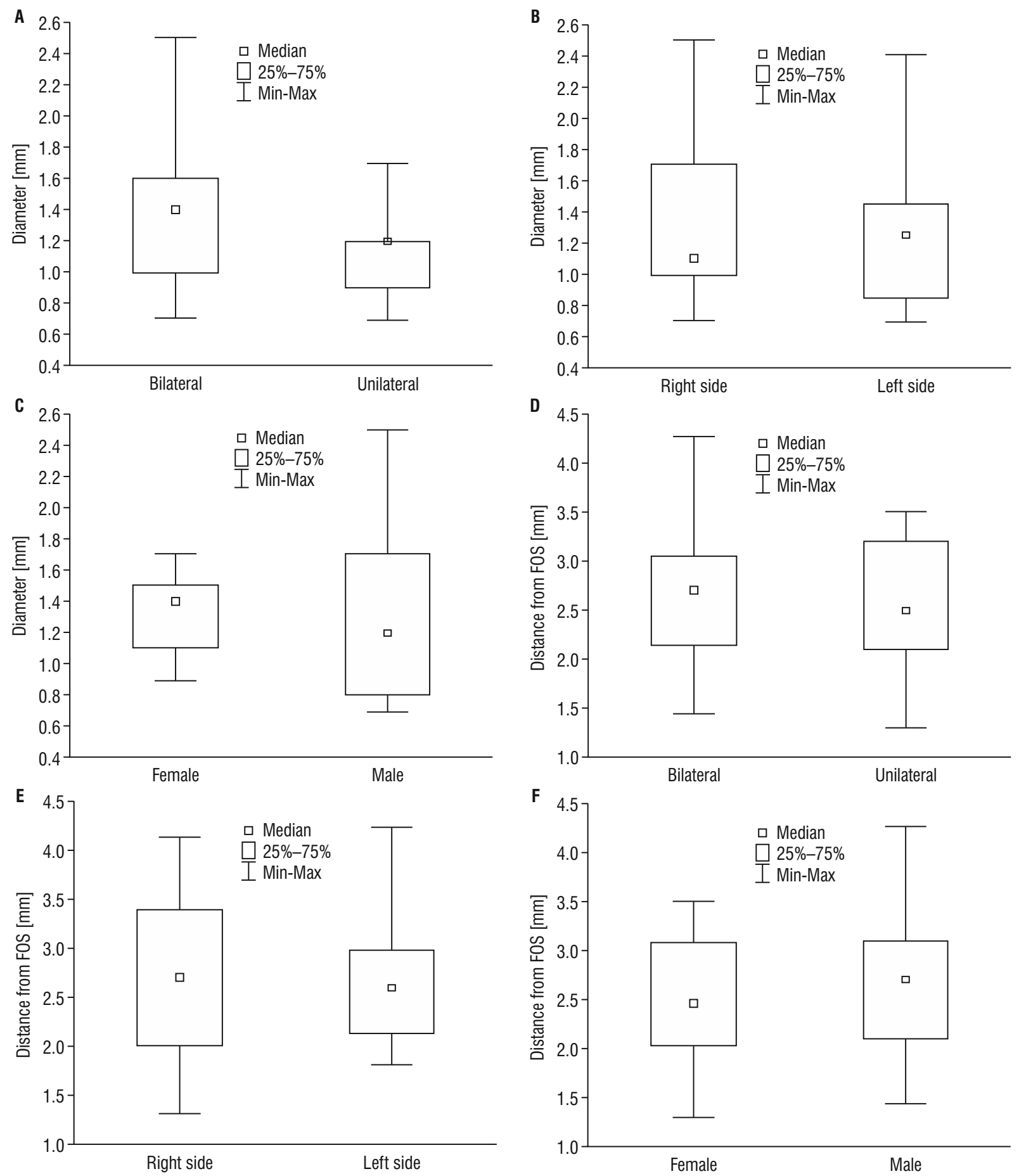

Figure 4. Graphic representation of bony canal morphometry based on the computed tomography scans assessment. Bony canal length and distance from superior orbital fissure (FOS) in association with uni-/bilaterality $(\mathbf{A}, \mathbf{D})$, side of occurrence $(\mathbf{B}, \mathbf{E})$ and gender $(\mathbf{C}, \mathbf{F})$, respectively.

Encyclopedia of Human Anatomic Variations [30], the $\mathrm{BC}$ is described as less common than the groove. In the newly published anatomical textbooks, the MMA grooves on the cranial base are designated as the sulcus arterious [33], the groove for the middle meningeal artery [34] or the groove for the middle meningeal vessels $[20 a, b]$.
Based on a review of other structures connected with the middle meningeal vessels listed in TA [9a, b], both the BC of the MMA and its grooves on the base of the skull are missing, even though they appeared to have a much higher prevalence than other structures, e.g., the foramen venosum (of Vesalius) with an incidence of $36 \%$ [4], which is named among the 

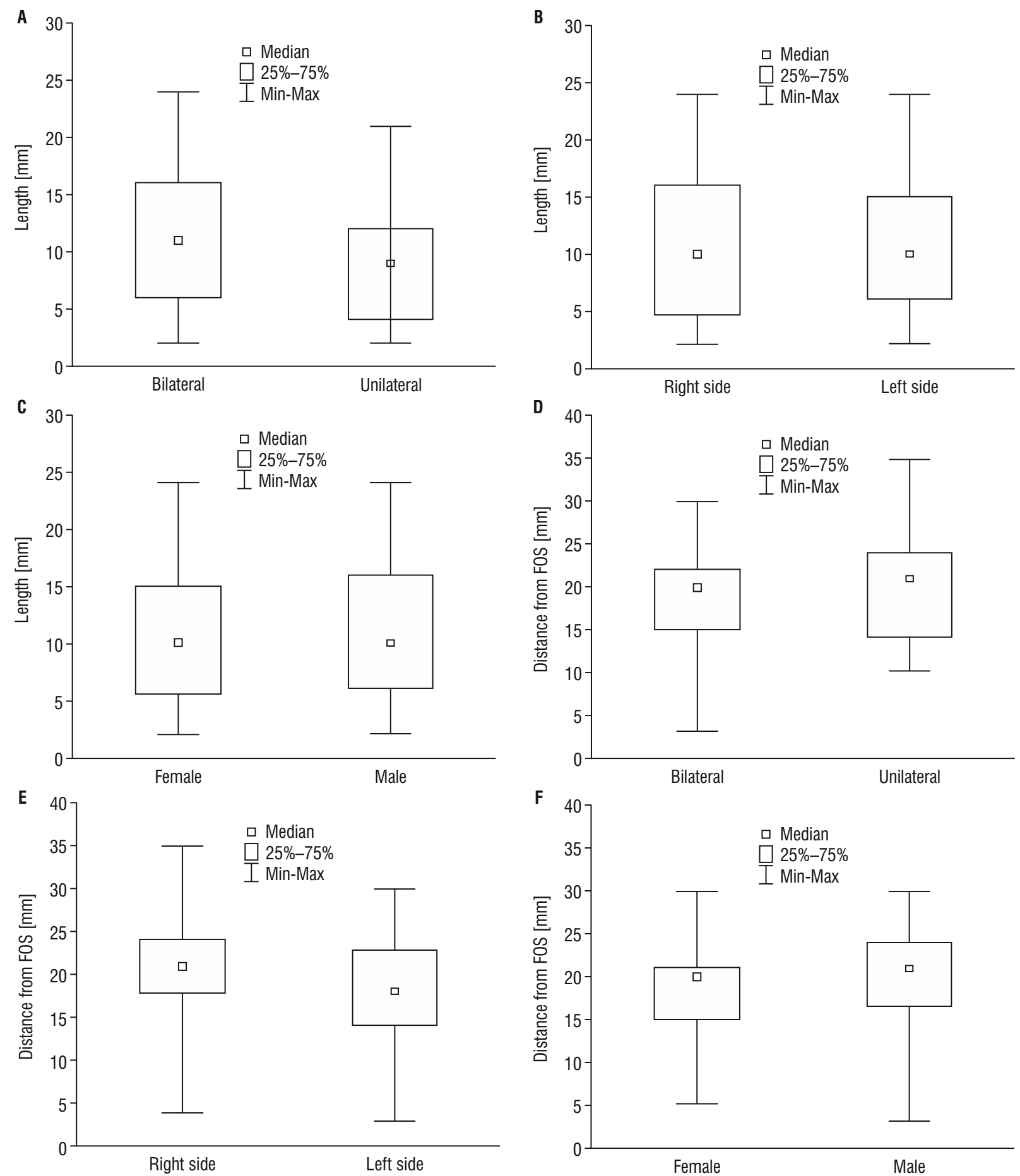

Figure 5. Graphic representation of bony canal morphometry based on the skull base assessment. Bony canal length and distance from superior orbital fissure (FOS) in association with uni-/bilaterality (A, D), side of occurrence $(\mathbf{B}, \mathbf{E})$ and gender $(\mathbf{C}, \mathbf{F})$, respectively. Bilateral canals were longer $(p=0.028)(A)$, distance from the superior orbital fissure was higher on the right side $(p=0.036)(E)$.

variations of the sphenoidal bone under the identifier A02.1.05.037 [9a]. Our study confirms the presence of the MMA within the grooves of the skull base (Fig. 7), although on the parietal bone these grooves were assumed to be produced by the meningeal veins [12].
Why are the bony canal and the MMA grooves missing in the TA, current anatomical atlases, and textbooks?

Based on our literature review, this fundamental question is challenging. The answer can be divided into the following two parts: why the $B C$ and MMA 

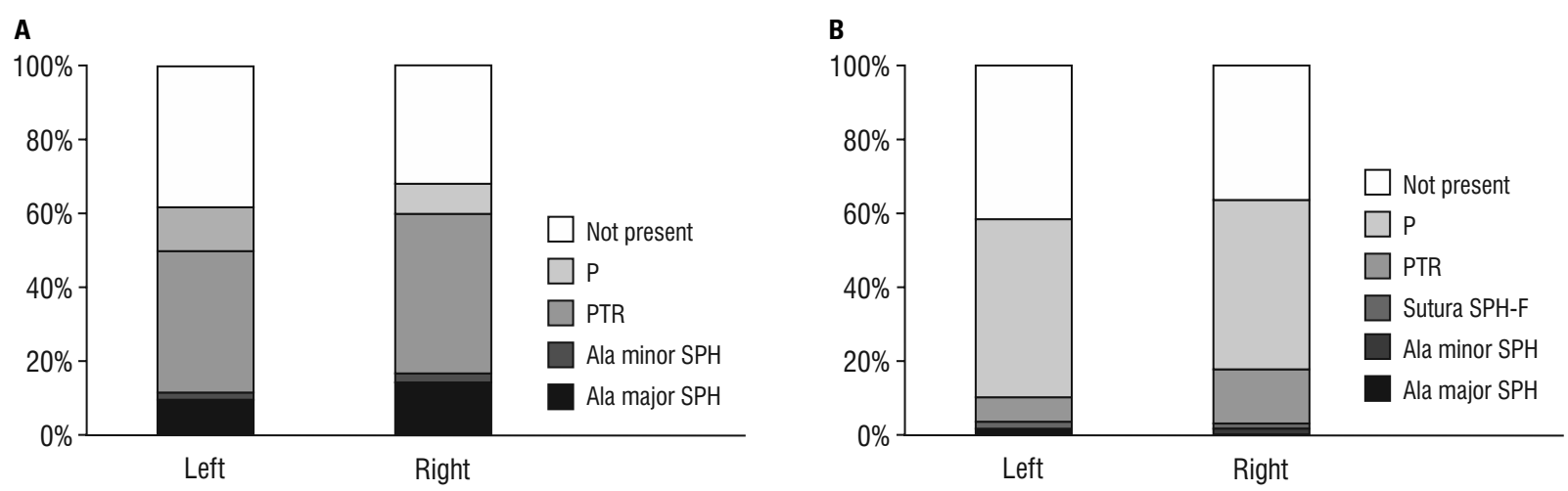

Figure 6. Skull base, bones of the canal initiation (A, beginning) and termination (B, end); P — parietal bone; PTR — pterion; SPH — sphenoidal bone; SPH-F — sphenofrontal suture.

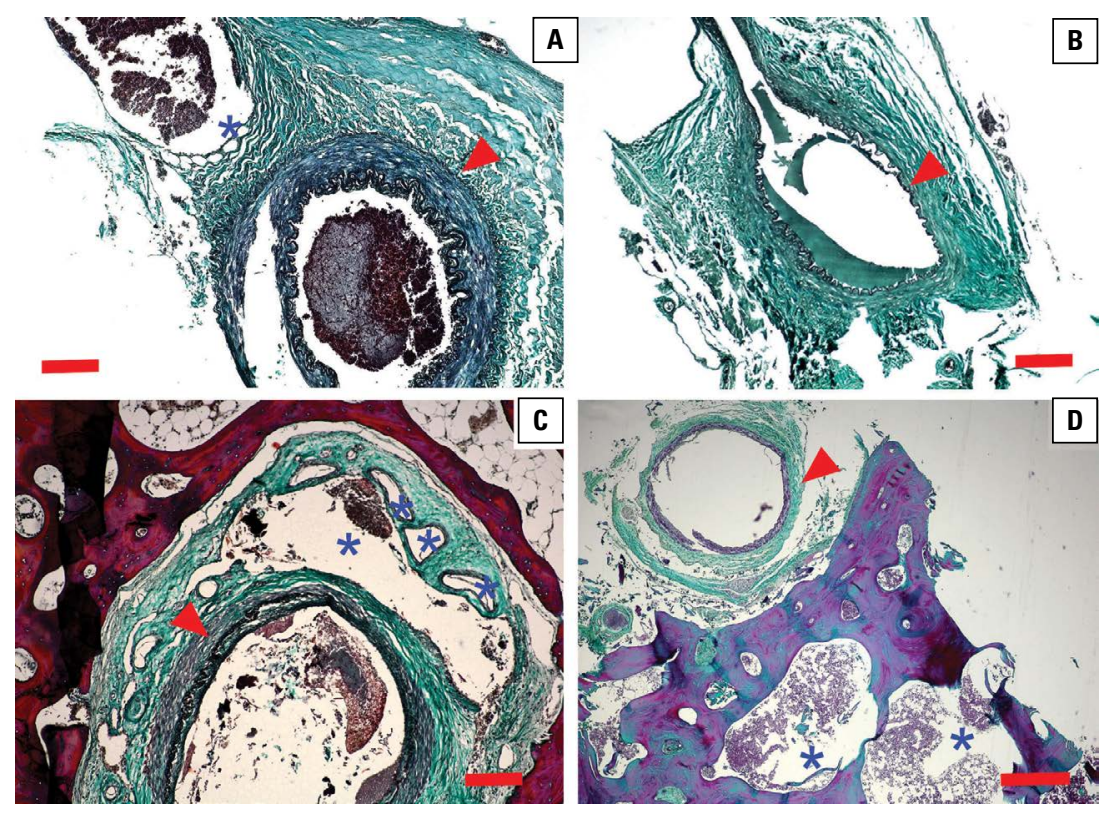

Figure 7. Meningeal vessels, Verhoeff's haematoxylin-green trichrome. Sites of histological sampling: at the foramen spinosum (A), at the meningeal bifurcation (B), through the bony canal at the pterion (C) and at the lesser wing of the sphenoidal bone (D). The middle meningeal artery (red arrowhead) and the accompanying vein/s (blue asterisk). Scale bar $200 \mu \mathrm{m}$.

grooves are omitted among the structures (I) on separate bones and (II) on the skull base. The current international standard for human anatomical terminology is based on the TA [6]. It was developed by the Federative Committee on Anatomical Terminology (FCAT) of the International Federation of Associations of Anatomists (IFAA) and was released in 1998. These standards specify generally accepted names of human gross anatomical structures. As such the TA provide for a summary of the precise, common anatomical vocabulary that is fundamental for communication within and between disciplines.

I) Remarkable exactness must be acknowledged in older anatomical textbooks. As early as 1896, Plum- mer [21], who described the presence of the canal as a structure of the parietal bone, noted that the $\mathrm{BC}$ began on the sphenoid bone in two cases, i.e. in $0.02 \%$. Gray's Anatomy is the only textbook we found that mentions the sphenoparietal canal (of Trolard), in particular in connection with the frontal branch of the MMA and the middle meningeal vein (sinus) [26a]. Interestingly, neither of studies that have focused on the BC (Table 1) nor on the sphenoparietal sinus [23] offered histological approval. Unlike other studies, our results show the most frequent $B C$ origin is in the pterion. If present, the exit was mainly found on the parietal bone (Fig. 6). From this finding, we suggest that the $B C$ may be at least partly damaged 

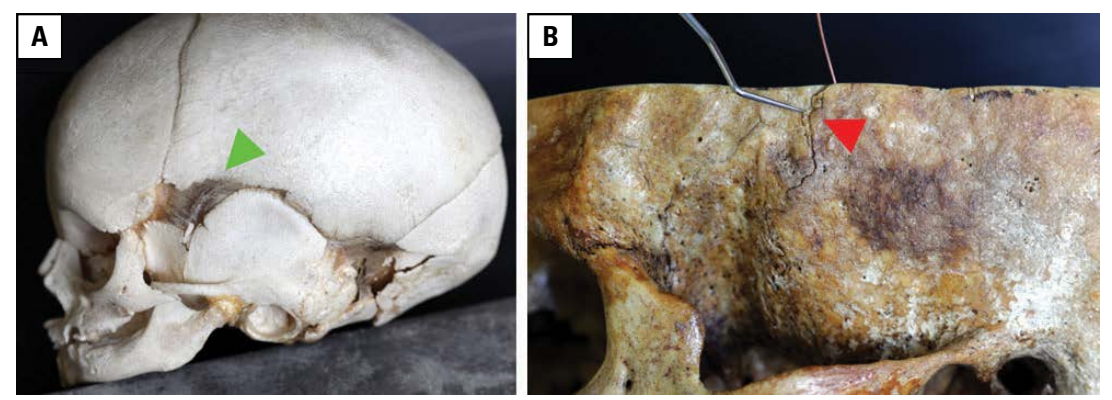

Figure 8. Human skull, pterion, sphenoidal fontanelle in a 6-month-old foetus (A). Lateral projection of the bony canal termination - the intersection of the sphenosquamosal, sphenoparietal and squamous sutures (B).

when separating the bones, such that it is either completely absent or simply cannot be distinguished. As such, the canal (groove) should be named in the upcoming version of the TA as the sphenoparietal canal (groove) among the structures of the base of the skull. For the grooves of the sphenoidal and temporal bones on the skull base, the bilateral incidence was greater than $75 \%$ (Tables $7 b-d$ ). Jones [12] supposed that the grooves on the parietal bone are more likely caused by the meningeal veins/sinuses, and we also found the course of the MMA alongside the veins (Fig. 7A, C, D). From this point of view, the term "groove for the middle meningeal vessels" would be more precise and could be utilized both with the skull base structures and with the separate bones.

II) Regarding the TA and description of the structures on the skull base, it is striking how inconsistent the named structures are [27]. For example, from structures of the Cranium and grooves for the dural sinuses, only the groove for the inferior petrosal sinus (A02.1.00.052) is named [9b]. On the other hand, the clivus has two different identifiers: on the base of the skull (A02.1.00.051) and on the occipital bone (A02.1.04.006).

As for the current anatomical literature, we assume that the structures were formerly skipped due to the need for text reduction in the older anatomical textbooks and that the omission has simply been copied since then.

\section{Skull base or CT scan morphometry - which is more accurate?}

Each method has pros and cons. When comparing $B C$ morphometry and incidence, significant differences can be noticed. The mean BC length in the CT scans was $17.67 \mathrm{~mm}$, compared to a length of $10.74 \mathrm{~mm}$ in the skulls. The beginning and the end of the BC, as well as the MMA grooves and impressions, can be found exactly in the skull base, while these can be only assumed in the CT scans. Additionally, the flexible ruler can follow the skull concavity, while the CT devices offer only linear measuring. On the other hand, CT is better for the canal length assessment, as on the skull bases only the shorter BCs were not cut and were included into the statistical analysis. The higher incidence in females, based on the CT scans, also seems to be a robust result, as the sex of a patient is known and cannot be questioned (unlike trying to determine the sex of a skull). Additionally, CT scans uniquely offer the measurement of the BC transverse diameter (Fig. 3A).

\section{Bony canal of the MMA from the developmental view}

Based on knowledge of developmental anatomy, anatomical variations in the origin and position of the MMA have previously been documented and explained $[2,3,30]$. Unlike other studies $[6,25]$ we suggest that the variation in $B C$ presence (or the groove depth) is not a pure outcome of embryological development, but that functional and structural relationships may play a crucial role [38]. It has been estimated, and our observations support this finding, that over $60 \%$ of $\mathrm{BCs}$ project into the pterion $[3,25]$ i.e., into the meeting point of the frontal, parietal, sphenoid and temporal bones on the lateral aspect of the skull (Fig. 8). The pterion is a site at which different types of sutures, namely, the squamous (i.e., the sphenosquamous) and serrate (i.e., sphenoparietal and sphenofrontal) sutures, meet. With respect to the sutural pattern, four pterion shapes have been distinguished, and their association with a variable course of the frontal branch of the MMA has been demonstrated [22]. This morphological variability indicates that complicated structural and functional relationships in our region of interest very likely develop during the ossification of the sphenoidal fon- 
tanelle, obliteration of which normally occurs within 3 months of birth [26c].

\section{Importance of the BC in neurosurgery}

Pterional craniotomy is a common, standardised surgical approach to the cranial cavity. To expose the intracranial internal carotid artery branching, it is often necessary to remove the lesser wing of the sphenoidal bone. In such a procedure, the MMA is usually injured. Nevertheless, the presence of the BC does not increase the risk of the surgery, it is just necessary to use another method for haemostasis. In particular, if the MMA passes through the bony canal, the bipolar coagulation cannot be used to stop the bleeding (the artery cannot be grasped with tweezers), and the bone wax is the method of choice then.

Over the past decades, there has been an increasing interest in the extracranial-intracranial arterial anastomosis. This bypass surgery has become a widely used surgical treatment for patients with intracranial ischaemic lesions [32]. Although some recent cadaveric studies suggested that the MMA could be a valuable donor vessel for bypass surgery [31], it is not commonly used. It is assumed that its ability to adapt to the increased flow needs is limited by fixation to the surrounding bones. Similarly, it also can be anticipated that the $B C$ presence increases the vessel wall rigidity and the risk of its injury. However, to our knowledge, no study demonstrating a relationship between the MMA BC and an increased risk of the epidural haematoma has been published yet.

\section{CONCLUSIONS}

Based on the CT scans of 378 patients, the incidence of the bony canal was $85.44 \%$ and was significantly higher in females than in males. Most of the canals were bilateral. The mean canal length was $17.67 \mathrm{~mm}$, the mean transverse diameter was $1.33 \mathrm{~mm}$, and the mean distance from the superior orbital fissure was $26.7 \mathrm{~mm}$. In the skull bases, the mean canal length was $10.74 \mathrm{~mm}$ and the mean distance from the FOS was $19.16 \mathrm{~mm}$. In the skull bases, most of the BCs had their origin in the pterion and terminated on the parietal bone. The BC incidence in the skulls was $70.07 \%$, the mean canal length was $10.74 \mathrm{~mm}$, and the mean distance from the superior orbital fissure was $19.16 \mathrm{~mm}$. The groove for the MMA (middle meningeal vessels) on the temporal and sphenoidal bones was present in $99.42 \%$ and $95.35 \%$, respectively. Presence of the middle meningeal vessels in the grooves on the base of the skull and in the $\mathrm{BC}$ was also demonstrated histologically. Although the $\mathrm{BC}$ and the grooves for the MMA on the skull base have been already described, they are omitted in current anatomical terminology and inconsistently depicted in contemporary anatomical literature. Due to the clinical importance of the meningeal vessels, also in acknowledgement of very high incidence of the studied structures, we suggest their addition as the sphenoparietal canal (groove), i.e., canalis (sulcus) sphenoparietalis, and the groove for the middle meningeal vessels, i.e., sulcus vasorum meningeorum mediorum, to the upcoming version of TA, section Cranium - Cranial Base. For more complete terminology, the latter should also be named under the same identifier with the structures of the sphenoidal and temporal bones.

We believe that our results may be useful in standardising not only the clinical anatomical terminology but also for the grafting of the MMA as a donor artery for extracranial-intracranial bypass.

\section{Acknowledgements}

The skulls were kindly provided by the First, Second and Third Faculty of Medicine, Charles University in Prague and Hradec Kralove, by the Faculty of Medicine in Brno and by the Faculty of Medicine Palacky University of Olomouc. We would also like to thank Ms. Veronika Varnerova, MD for providing her research results, Dr. Sarah Leupen, PhD for language proofreading and Ms. Marketa Slajerova, MBA for her excellent histological assistance.

\section{Funding source}

This study was supported by Charles University in Prague (Grants SVV-2019 No. 260392; Research Fund Progress Q37 and Q39) and by the National Sustainability Programme I (NPU I; No. LO1503) provided by the Ministry of Education, Youth and Sports of the Czech Republic. Histological evaluation was supported by the European Regional Development Fund-Project "Application of Modern Technologies in Medicine and Industry" (No. CZ.02.1.01/0.0/0.0/1 7_048/0007280).

\section{REFERENCES}

1. Agresti A, Coull B. Approximate Is Better than "Exact" for Interval Estimation of Binomial Proportions. Am Stat. 1998; 52(2): 119, doi: 10.2307/2685469.

2. Alkhazali TJ. Anatomical variation in the course, branches, and metrical measurement of the grooves, of the middle meningeal artery inside the skull. Med J Tikrit. 2009; 2: 38-41. 
3. Chandler S, Derezinski $C$. The variations of the middle meningeal artery within the middle cranial fossa. Anatl Record. 1935; 62(3): 309-319, doi: 10.1002/ar.1090620309.

4. Berlis A, Putz R, Schumacher M. Direct and CT measurements of canals and foramina of the skull base. Br J Radiol. 1992; 65(776): 653-661, doi: 10.1259/0007-1285-65-776653, indexed in Pubmed: 1393389.

5. Bertelli E, Regoli M, Bracco S. An update on the variations of the orbital blood supply and hemodynamic. Surg Radiol Anat. 2017; 39(5): 485-496, doi: 10.1007/s00276-0161776-9, indexed in Pubmed: 27830321.

6. Da Si, Ellwanger J, Da Ro, et al. Origins of the middle meningeal artery and its probable embryological mechanism: a review. J Morphol Sci. 2013; 30: 69-72.

7. Dauber W. Pocket Atlas of Human Anatomy: Founded by Heinz Feneis. 5th Ed. Thieme, Taubingen 2011: 23 (a), 236 (b), 30 (c).

8. Drake RL. Terminologia Anatomica: International Anatomical Terminology. 2 nd Ed. Thieme, Stuttgart 2011.

9. FCAT: Terminologia anatomica: international anatomical terminology. Georg Thieme Verlag, Stuttgart: 11 (a), 8, 9 (b), 13 (c).

10. FIPAT. Terminologia neuroatomica federative international programme for anatomical terminology. 2017. http:// FIPAT.library.dal.ca.

11. Idriz S, Patel JH, Ameli Renani S, et al. CT of normal developmental and variant anatomy of the pediatric skull: distinguishing trauma from normality. Radiographics. 2015; 35(5): 1585-1601, doi: 10.1148/rg.2015140177, indexed in Pubmed: 26207580.

12. Jones FW. On the grooves upon the ossa parietalia commonly said to be caused by the Arteria Meningea Media. J Anat Physiol. 1912; 46: 228-238.

13. Kachlik D, Baca V, Bozdechova I, et al. Anatomical terminology and nomenclature: past, present and highlights. Surg Radiol Anat. 2008; 30(6): 459-466, doi: 10.1007/ s00276-008-0357-y, indexed in Pubmed: 18488135.

14. Kachlik D, Bozdechova I, Cech P, et al. Mistakes in the usage of anatomical terminology in clinical practice. Biomed Pap Med Fac Univ Palacky Olomouc Czech Repub. 2009; 153(2): 157-161, doi: 10.5507/bp.2009.027, indexed in Pubmed: 19771143.

15. Kachlik D, Musil V, Baca V. Terminologia Anatomica after 17 years: inconsistencies, mistakes and new proposals. Ann Anat. 2015; 201: 8-16, doi: 10.1016/j.aanat.2015.04.006, indexed in Pubmed: 26094127.

16. Kachlik D, Musil V, Baca V. Contribution to the anatomical nomenclature concerning general anatomy and anatomical variations. Surg Radiol Anat. 2016; 38(7): 757-765, doi: 10.1007/ s00276-016-1627-8, indexed in Pubmed: 26946463.

17. Kachlík D, Musil V, Baca V. A plea for extension of the anatomical nomenclature. Part 1: Nervous system and senses. Folia Morphol. 2017; 76(2): 168-177, doi: 10.5603/ FM.a2016.0064, indexed in Pubmed: 27813631.

18. Manzanares-Céspedes MC. On-line Terminologia Anatomica: a proposal. Anat Sci Educ. 2010; 3(3): 154-155, doi: 10.1002/ase.149, indexed in Pubmed: 20496437.

19. Morris H, Jackson CM. Morris's human anatomy; a complete systematic treatise by English and American authors. P. Blakiston's Son, Philadelphia 1914: 354.

20. Netter FH. Atlas of Human Anatomy. 6th Ed. Elsevier, Philadelphia 2014: 13 (a), 11 (b).

21. Plummer SC. III. Research on the surgical anatomy of the middle meningeal artery. Ann Surg. 1896; 23(5): 540-572, doi: 10.1097/00000658-189601000-00100, indexed in Pubmed: 17860301.
22. Praba MA, Venkatramaniah C. Morphometric Study of different types of Pterion and it's relation with middle meningeal artery in dry skulls of Tamil Nadu. J Pharm Biomed Sci. 2012; 21(04).

23. San Millán RD, Fasel JHD, Rüfenacht DA, et al. The sphenoparietal sinus of breschet: does it exist? An anatomic study. AJNR Am J Neuroradiol. 2004; 25: 112-120.

24. Schuenke M, Schulte E, Schumacher U, Gilroy AM, MacPherson BR. (eds). Atlas of Anatomy Latin Nomenclature. 3rd Ed. Thieme, New York 2017: 571 (a); 511, 515 (b).

25. Shimizu S, Hagiwara $H$, Utsuki S, et al. Bony tunnel formation in the middle meningeal groove: an anatomic study for safer pterional craniotomy. Minim Invasive Neurosurg. 2008; 51(6): 329-332, doi: 10.1055/s-0028-1085430, indexed in Pubmed: 19061142.

26. Standring S. Gray's Anatomy: The Anatomical Basis of Clinical Practice. 41st Ed. Elsevier Limited, China 2016: 439 (a), 427 (b), 424 (c).

27. Strzelec B, Chmielewski PP, Gworys B. The Terminologia Anatomica matters: examples from didactic, scientific, and clinical practice. Folia Morphol. 2017; 76(3): 340-347, doi: 10.5603/FM.a2016.0078, indexed in Pubmed: 28026851

28. Ten Donkelaar HJ, Broman J, Neumann PE, et al. Towards a Terminologia Neuroanatomica. Clin Anat. 2017; 30(2): 145-155, doi: 10.1002/ca.22809, indexed in Pubmed: 27910135.

29. Trolard P. Les veines méningées moyennes. Rev Sci Biol. 1890: 485-499.

30. Tubbs RS, Shoja MM, Loukas M. Bergman's Comprehensive Encyclopedia of Human Anatomic Variation. John Wiley \& Sons, New York. 2016: 482, doi: 10.1002/9781118430309.

31. Vigo V, Dones F, Di Bonaventura R, et al. Middle meningeal artery to premeatal anterior inferior cerebellar artery bypass via anterior petrosectomy: an anatomic feasibility study. World Neurosurg. 2019; 123: e536-e542, doi: 10.1016/j. wneu.2018.11.207, indexed in Pubmed: 30521956.

32. Wang L, Cai Li, Qian H, et al. The in situ side-to-side bypass technique: a comprehensive review of the technical characteristics, current anastomosis approaches, and surgical experience. World Neurosurg. 2018; 115: 357-372, doi: 10.1016/j.wneu.2018.04.173, indexed in Pubmed: 29729474.

33. Waschke J, Böckers TM, Paulsen F. Sobotta Anatomy Textbook. 1st Ed. Elsevier, Munich, Germany 2019: 415.

34. Weber EC, Vilensky JA, Carmichael SW, Lee KS. Netter's Concise Radiologic Anatomy. 2nd Ed. Elsevier, Philadelphia, USA 2019: 4, 5.

35. Whitmore I. Terminologia Anatomica includes terms in English for all scientists writing in English. Anat Sci Educ. 2009; 2(3): 141, doi: 10.1002/ase.88, indexed in Pubmed: 19496164.

36. Whitmore I. Terminologia anatomica: new terminology for the new anatomist. Anat Rec. 1999; 257(2): 50-53, doi: 10.1002/(SICI)1097-0185(19990415)257:2<50::AIDAR4>3.0.CO;2-W, indexed in Pubmed: 10321431.

37. Yu J, Guo Y, Xu B, et al. Clinical importance of the middle meningeal artery: A review of the literature. Int J Med Sci. 2016; 13(10): 790-799, doi: 10.7150/ijms.16489, indexed in Pubmed: 27766029.

38. Yu JC, McClintock JS, Gannon F, et al. Regional differences of dura osteoinduction: squamous dura induces osteogenesis, sutural dura induces chondrogenesis and osteogenesis. Plast Reconstr Surg. 1997; 100(1): 23-31, doi: 10.1097/00006534-199707000-00005, indexed in Pubmed: 9207655. 